\title{
Akut sağ üst kadran ağrısının nadir bir nedeni: Spontan intrahepatik safra yollarına rüptüre kist hidatik ve çok kesitli bilgisayarlı tomografi bulguları
}

An unusual cause of acute right upper quadrant pain: spontaneous intrabiliary rupture of hepatic hydatid cyst with multidetector computed tomography findings

Fuat Özkan*, Mehmet Fatih İnci, Selim Bozkurt, Nuri Özcan, Mürvet Yüksel, Eyüp Mehmet Pircanoğlu

Radyoloji Anabilim Dalı (Yrd. Doç. Dr. F. Özkan, Yrd. Doç. Dr. M. F. İnci, Dr. N. Özcan, Yrd. Doç. Dr. M. Yüksel), Acil Tıp Anabilim Dalı (Dr. S. Bozkurt), Genel Cerrahi Anabilim Dalı (Dr. E. M. Pircanoğlu), Kahramanmaraş Sütçü İmam Üniversitesi Tıp Fakültesi, TR-46050 Kahramanmaraş

\section{Özet}

Kist hidatik primer olarak karaciğerde görülen parazitik bir hastalıktır. Hidatik kistler uzunca bir süre asemptomatik kalabilmelerine rağmen, rüptür ya da piyojenik infeksiyon gibi komplikasyonlarına bağlı olarak semptomatik olabilirler. İntrabilier rüptür karaciğer kist hidatiğinin en ciddi komplikasyonlarından biridir. Hastalar genellikle ağrı ve sarılık şikayetiyle başvururlar. Bu yazıda akut sağ üst kadran ağrısı ve sarılıkla başvuran karaciğer kist hidatik intrabilier rüptürünün radyolojik görüntüleme bulgularını sunmayı amaçladık. Altmış dört yaşındaki hasta ani başlayan sağ üst kadran ağrısı ve sarılık şikayetiyle acil servise başvurdu. Batın ultrasonografisinde karaciğer sol lob medial segmente $7 \times 4 \mathrm{~cm}$ boyutlu lobule konturlu, basınçlı görünümünü kaybetmiş olan ve sol ana safra kanalı ile ilişkili hidatik kist ile uyumlu lezyon saptandı. Sagittal reformat çok kesitli bilgisayarlı tomografide kistin safra yolları ile ilişkisi net biçimde izlendi. Olgu opere edildiğinde çok kesitli bilgisayarlı tomografide bulguları teyit edildi. Hastalığın endemik olduğu bölgelerde sağ üst kadran ağrısı ile başvuran hastalarda karaciğer kist hidatiğinin safra yollarına rüptürü ayırıcı tanıda akılda bulundurulması gereken bir durumdur. Olguların çoğunluğunda ultrasonografi tanı için yeterli olmakla birlikte çok kesitli bilgisayarlı tomografide rüptür lokalizasyonunu göstermede oldukça faydalıdır.

Anahtar sözcükler: Ekinokokkozis, hepatik, spiral bilgisayarlı tomografi

\begin{abstract}
Hydatid disease presents as hydatid cysts primarily in the liver. Although hepatic hydatid cysts may be asymptomatic for many years, they may be symptomatic because of its complications such as expansion, rupture, and pyogenic infection. Rupture of the hepatic hydatid cysts into the biliary tract is one of the most serious complication and is frequently related to over enlargement of the cyst. Patients with this disease usually have pain or jaundice. In this paper, we present radiological imaging findings of an hepatic hydatid cysts ruptured into left main intrahepatic biliary duct presented as the acute right upper quadrant pain and jaundice. A 64-year-old man was admitted to the emergency department for suddenly onset of right upper quadrant pain and jaundice. Abdominal ultrasonography showed that cystic lesion measuring about $7 \times 4 \mathrm{~cm}$ in diameters with lobulated contour adjacent gallbladder and communication between cyst and left main intrahepatic biliary duct. Abdominal computed tomography confirmed this findings and the patient surgically treated with pericystectomy and confirmed CT findings intraoperatively. The post-operative course was uneventful. Intrabiliary rupture of hepatic hydatid cysts must be considered in the differential diagnosis of patients presenting with right upper quadrant pain in areas where the disease is endemic. Early diagnosis with ultrasound, CT and appropriate treatment are essential for favorable outcome.
\end{abstract}

Keywords: Hydatid cyst, hepatic, spiral computed tomography 
Geliş tarihi/Received: 01 Ekim 2012; Kabul tarihi/Accepted: 29 Ocak 2013

\author{
*Iletişim adresi: \\ Dr. Fuat Ozkan, Radyoloji Anabilim Dalı, Kahramanmaraş Sütçü İmam Üniversitesi, Tıp \\ Fakültesi, TR-46050 Kahramanmaraş. E-posta: drfozkan@yahoo.com
}

Bu çalışma, 3-6 Ekim 2012 tarihinde Antalya'da düzenlenecek olan 7. Avrupa acil tıp kongresinde yazılı poster olarak kabul edilmiştir.

\title{
Giriș
}

Hidatik hastalık doğada yaygın olarak bulunan Echinococcus granulosus ile meydana gelen paraziter bir enfeksiyon hastalığı olup ülkemizde sık olarak karşımıza çıkmaktadır. Vücudun herhangi bir organını tutabilse de en sık tutulan organ karaciğerdir [1-3]. Kist hidatiklerin bazıları yılda 1-30 mm büyüyebilir, bazıları hiç değişiklik göstermez, bazıları da kollabe olup tamamen kaybolabilir. İntrakistik basınç artışına sekonder internal veya eksternal travmatik veya spontan rüptürü olabilir [4-6]. Safra kanalları ile ilişkili olduğunda ise kistin safra yollarına spontan rüptürü olabilir [4]. Safra yollarına rüptüre olduğunda opere edilmezse ölümcül sonuçlar doğurabilir [7]. Bu olguda akut sağ üst kadran ağrısının nadir bir nedeni olan spontan intrabiliyer karaciğer kist hidatik rüptürünün ultrasonografi (US) ve çok kesitli bilgisayarlı tomografi (ÇKBT) bulguları sunulmaktadır.

\section{Olgu sunumu}

Altmış-dört yaşındaki erkek hasta batın sağ üst kadranda ani başlayan ve gittikçe artan ağrı ve sarılık şikâyeti ile acil servise başvurdu. Ayrıca bulantı, kusma ve halsizlik gibi nonspesifik semptomları da mevcuttu. Travma öyküsü bulunmamaktaydı. Yapılan fizik muayenede sağ üst kadranda hassasiyet ve minimal hepatomegali saptandı. Laboratuvar incelemesinde total bilurubin $10,8 \mathrm{mg} / \mathrm{dL}$, alkalen fosfataz $241 \mathrm{IU} / \mathrm{L}$ idi. Tam kan sayımında anormallik yoktu. Hastaya abdominal US ve kontrastlı ÇKBT tetkikleri yapıldı. Yapılan US incelemede karaciğer sol lob medial_segmente $7 \times 4 \mathrm{~cm}$ boyutlu lobule konturlu, basınçlı görünümünü kaybetmiş olan ve sol ana safra kanalı ile ilişkili hidatik kist ile uyumlu lezyon saptandı, kistin inferiormedial duvarında bütünlük kaybı ve intrahepatik safra yolları ile iştiraki izlendi (Resim 1). Ayrıca US ve ÇKBT incelemede sol lobdaki lezyona ek olarak sağ lob anteriorda $6 \mathrm{~cm}$ çapında cidarında milimetrik kalsifikasyon bulunan dejenere hidatik kist lezyonu saptandı (Resim 2). Sagital reformat ÇKBT görüntülerde de kistin safra yolları ile ilişkisi net biçimde izlendi (Resim 3). Koledok hafif geniş olup internal ekojeniteler içeriyordu. Bu bulgularla hidatik kistin safra yollarına rüptürü düşünüldü. Olgu opere edildi, operasyon esnasında parsiyel kistektomi, kolesistektomi, koledokotomi ve T-tüp drenajı yapıld1. Sağ lobdaki kiste parsiyel kistektomi yapıldı. Tanımız cerrahi ve histopatolojik olarak doğrulandı. Operasyon sonrası birkaç ay süreyle kiste yönelik medikal tedavi uygulandı. 


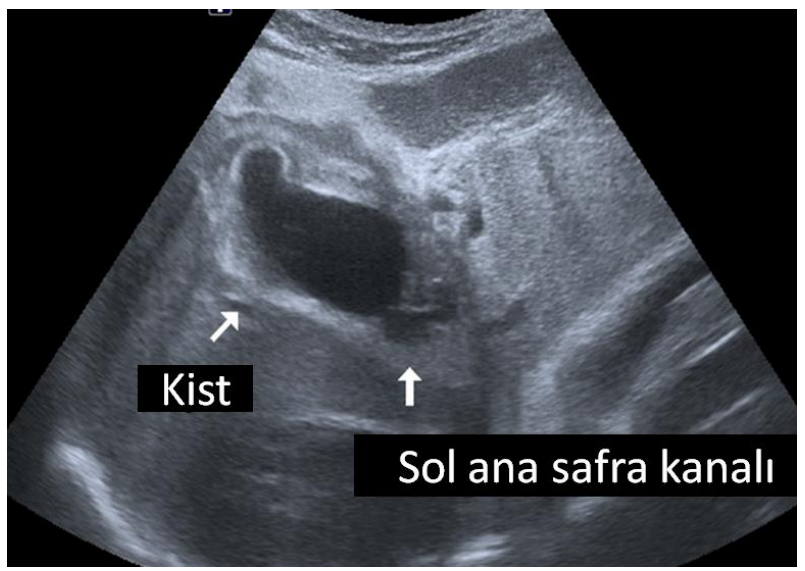

Resim 1. US incelemede karaciğer sol lob medial segmente $7 \times 4 \mathrm{~cm}$ boyutlu lobule konturlu, basınçlı görünümünü kaybetmiş olan ve sol ana safra kanalı ile ilişkili hidatik kist ile uyumlu lezyon saptandı, kistin inferiormedial duvarında bütünlük kaybı ve intrahepatik safra yolları ile iştiraki izlenmektedir (oklar).

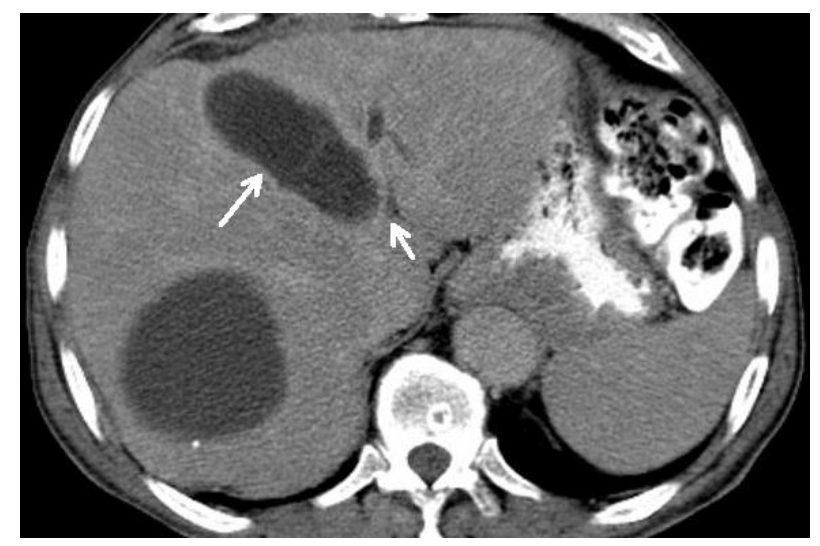

Resim 2. ÇKBT incelemede rüptüre kist hidatik lezyonuna (uzun ok) ve komşuluğundaki dilate safra yolu izlenmektedir (kısa ok). Ayrıca sağ lob anteriorda $6 \mathrm{~cm}$ çapında cidarında milimetrik kalsifikasyon bulunan dejenere hidatik kist lezyonu saptanmıştır.

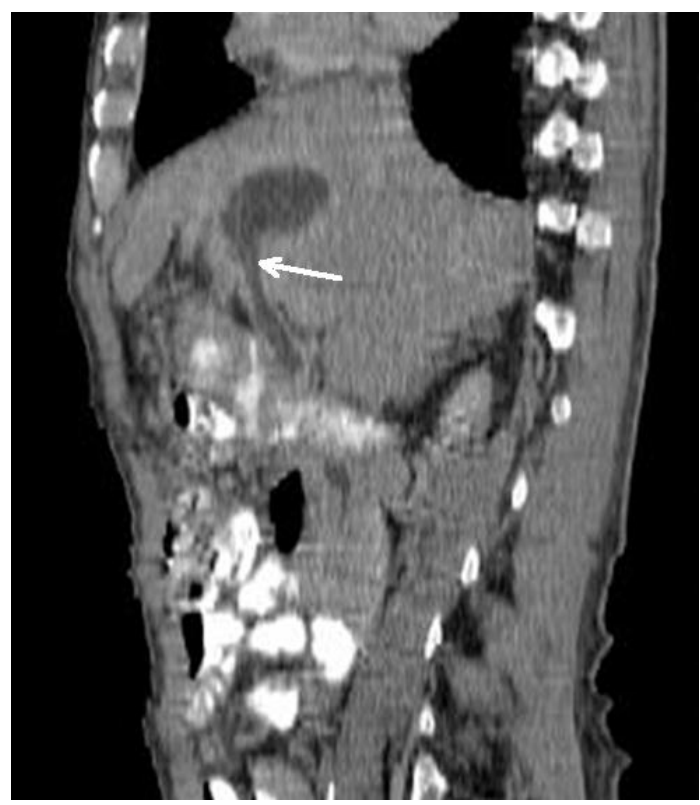

Resim 3. Sagital reformat ÇKBT görüntüde kistin safra yolları ile ilişkisi net biçimde izlenmektedir (ok). 


\section{Tartışma}

Karaciğer kist hidatiği, Echinococcus granulosus adlı bir parazitin neden olduğu, dünya üzerinde endemik hastalığa yol açan parazitik bir enfeksiyondur. Hidatidoz ülkemizde yaygın olarak görülen bir sağlık problemidir [1-13]. Kist hidatik tanısında US ve BT inceleme iki önemli görüntüleme yöntemleridir. Ayrıca tanıda, manyetik rezonansgörüntüleme (MRG) kullanılmakta ancak diğer iki görüntüleme yöntemlerinden farklı bir bilgi vermemektedir [8, 9]. Laboratuar testler spesifik olmamakla birlikte yardımcı olmaktadır. Karın sağ üst kadran ağrısı yada epigastrik ağrı en sık görülen klinik bulgudur. Halsizlik, ateş, dispepsi ve bulantı nonspesifik bulgulardır. En önemli komplikasyonları rüptür ve/veya anafilaktik şok, enfeksiyon ve safra yolu obstrüksiyonudur [3, 12]. Hepatik hidatik kistin safra yollarına rüptürü en ciddi komplikasyonudur [4, 13]. Komplike kistler konusunda literatür bilgileri net değildir. Kistin büyüklüğü ile safra yolları arasındaki ilişki kesin olmamakla birlikte, Atlı ve ark. [13] $14.5 \mathrm{~cm}$ üzeri kistlerde, multiloküle ve dejenere kistlerde safra yollariile ilişkiden şüphelenilmesi gerektiğini vurgulamaktadırlar.

Hidatik kist rüptürlerinin üç tipi vardır: Birinci tip olan contained (saklı) rüptürde, hidatik sıvı kistte bulunan endokist ile perikist arasına sızar ve sıvı dışarı boşalmaz. İkinci tip olan communicating rüptürde, kist komşuluğundaki safra yollarına açılır. Bu da kist ile safra kanalı arasındaki bağlantının büyüklüğüne göre basit ve aşikâr rüptür diye ikiye ayrılır. Basit rüptürde safra yollarına hidatik materyal geçişi olmaz ve genelde asemptomatiktir. Ancak zamanla aşikâr rüptür meydana gelebilir. Aşikâr rüptürde safra yollarına bol miktarda hidatik materyal geçişi olup obstrüktif semptomlar yapabilir [4]. Üçüncü tip olan direkt rüptürde, kist içeriği plevra boşluğu periton veya perikard boşluğuna boşalabilir $[1,5,6]$. Hidatik kistin seröz boşluklara direkt açılımı allerji ve anaflaksiye neden olabilir [4]. Bizim olgumuz da spontan intrahepatik safra yollarına rüptüre communicating tipin aşikâr formuna uymaktaydı.

Hastalar genellikle karın ağrısı, sarılık, ateş, akut kolanjit nadiren pankreatit ve karaciğer absesi semptomlarıyla başvururlar [4]. Laboratuar bulguları genellikle nonspesifik olup tanı çoğunlukla klinik olarak şüphelenilen vakalarda radyolojik görüntüleme yöntemleriyle konur. US ilk kullanılan görüntüleme yöntemi olup sarılı̆̆ı olan bir hastada karaciğerde hidatik kistin görülmesi, duvarının düzensiz olup bütünlüğünün bozulmuş olması ve ana biliyer kanalda genişleme saptanması ile tanı konabilir. US ile birlikte BT kullanımı doğru tanı oranını arttırır. Özellikle ÇKBT ile kistin lokalizasyonunu, morfolojisini, içeriğini, ve komşu yapılarla ilişkisini daha net olarak ortaya koyar. Multiplanar reformat görüntüler kist duvarında devamsızlığın görüldüğü rüptür lokalizasyonu ile rüptürün açıldığ 1 genişlemiş safra kanalını daha net biçimde ortaya koyabilir.

Sonuç olarak hastalığın endemik olduğu bölgelerde akut sağ üst kadran ağrısı ile başvuran hastalarda karaciğer kist hidatiğinin safra yollarına rüptürü ayırıcı tanıda akılda bulundurulması gereken bir klinik durumdur. Olguların çoğunluğunda US tanı için yeterli olmakla birlikte ÇKBT rüptür lokalizasyonunu göstermede oldukça faydalıdır.

\section{Kaynaklar}

1. Şahin E, Karadayı Ş, Nadir A, Kaptanoğlu M. Diyafragmatik kist hidatik: olgu sunumu. Cumhuriyet Tip Derg 2009; 31: 452-5.

2. Kurt A, Onuray F, Kurt B, Çulhadaroğlu AB. Primer intramusküler hidatik kist: olgu sunumu. Cumhuriyet Tip Derg 2009; 31: 445-7.

3. Döleş AK, Eren ŞH, Döleş FT, Kukul MFG, Korkmaz İ, Coşkun A, Karadayı Ş. A case of cyst hydatid has a family history with pulmonary, hepatic and splenic involvement. Cumhuriyet Tip Derg 2009; 31: 288-92.

4. Erdoğmuş B, Yazıcı B, Şafak AA, Kunduracı E, Özdere BA. Spontan İntrahepatik Safra Yollarına Rüptüre Kist Hidatik: Olgu Sunumu. Düzce Tıp Fakültesi Dergisi 2003; 5: 35-7. 
5. Arslan S, Bingöl A, Berk S, Gümüş C, Akkurt İ. Bronchobiliary fistula: A rare case. Cumhuriyet Tip Derg 2011; 33: 361-4.

6. Değer KC, Dalgıç T, Ulaş M, Bostancı EB, Seven C, Akoğlu M. A recurrent cyst hydatic abscess fistulised to the bronchial tree. Cumhuriyet Tip Derg 2012; 34: 98-102.

7. Castanares-Zapatero D, Laterre PF. Ruptured hydatid cyst in a patient with shock. Hepatobiliary Pancreat Dis Int 2009; 8: 638-9.

8. Sayek İ, Tirnaksız MB, Doğan R. Cystic Hydatid Disease: Current trends in diagnosis and management. Surg Today 2004; 34: 987-96.

9. Şahin DA, Kuşaslan R, Türel KS, Akbulut G, Arıkan Y, Dilek ON. Karaciğer Kist Hidatik Olgularımızda Cerrahi Tedavi ve ERCP ile Sfinkterotominin Etkinliği. Kocatepe Tıp Dergisi 2006; 7: 11-6.

10. Kayaalp C, Bzeizi K, Demirbag AE, Akoglu M. Biliary complications after hydatid liver surgery: incidence and risk factors. J Gastrointest Surg 2002; 6: 706-12.

11. Yorganc1 K, Sayek I.Surgical treatment of hydatid cysts of the liver in the era of percutaneous treatment. Am J Surg 2002; 184: 63-9.

12. Kjossev KT, Losanoff JE. Classification of hydatid liver cysts. J Gastroenterol Hepatol 2005; 20: 352-9.

13. Atlı M, Kama NA, Yüksek YN, Doganay M, Gozalan U, Kologlu M, Daglar G. Intrabiliary rupture of a hepatic hydatid cyst: associated clinical factors and proper management. Arch Surg 2001; 136: 1249-55. 